\title{
BMJ Open Adenovirus and RNA-based COVID-19 vaccines' perceptions and acceptance among healthcare workers in Saudi Arabia: a national survey
}

\author{
Mohamad-Hani Temsah (D) , ${ }^{1,2}$ Mazin Barry (D) ,1,3 Fadi Aljamaan (D) ,1,4 \\ Abdullah Alhuzaimi, ${ }^{1,5}$ Ayman Al-Eyadhy (1) , 1,2 Basema Saddik (1) ,,7 \\ Abdulkarim Alrabiaah, ${ }^{1,2}$ Fahad Alsohime (1) ,1,2 Ali Alhaboob (D) ,1,2 \\ Khalid Alhasan (D) , ${ }^{1,2}$ Ali Alaraj (D) , ${ }^{8,9}$ Rabih Halwani (D) , ,,7 \\ Nurah Maziad Alamro (D) , ,10 Fatimah S Al-Shahrani, ${ }^{1,3}$ Amr Jamal (D) ,1,10,11 \\ Sarah Alsubaie, ${ }^{1,2}$ Ziad A Memish (1) , ${ }^{12,13}$ Jaffar A Al-Tawfiq (1D) 14,15,16
}

To cite: Temsah M-H, Barry M, Aljamaan $\mathrm{F}$, et al. Adenovirus and RNA-based COVID-19 vaccines' perceptions and acceptance among healthcare workers in Saudi Arabia: a national survey. BMJ Open 2021;11:e048586. doi:10.1136/ bmjopen-2020-048586

- Prepublication history and supplemental material for this paper is available online. To view these files, please visit the journal online (http://dx.doi org/10.1136/bmjopen-2020048586).

M-HT and MB contributed equally.

Received 02 January 2021 Accepted 17 May 2021

D) Check for updates

(C) Author(s) (or their employer(s)) 2021. Re-use permitted under CC BY-NC. No commercial re-use. See rights and permissions. Published by BMJ.

For numbered affiliations see end of article.

Correspondence to Dr Amr Jamal; med.researcher.2020@gmail. com

\section{ABSTRACT}

Objectives The aim of this study was to compare the perception, confidence, hesitancy and acceptance rate of various COVID-19 vaccine types among healthcare workers (HCWs) in Saudi Arabia, a nation with Middle East respiratory syndrome coronavirus experience.

Design National cross-sectional, pilot-validated questionnaire.

Setting Online, self-administered questionnaire among HCWs.

Participants A total of 2007 HCWs working in the Kingdom of Saudi Arabia participated; 1512 (75.3\%) participants completed the survey and were included in the analysis.

Intervention Data were collected through an online survey sent to HCWs during 1-15 November 2020. The main outcome measure was HCW acceptance of COVID-19 candidate vaccines. The associated factors of vaccination acceptance were identified through a logistic regression analysis and via measurement of the level of anxiety, using the Generalised Anxiety Disorder 7 scale.

Results Among the 1512 HCWs who were included, $62.4 \%$ were women, $70.3 \%$ were between 21 and 40 years of age, and the majority (62.2\%) were from tertiary hospitals. In addition, $59.5 \%$ reported knowing about at least one vaccine; $24.4 \%$ of the participants were sure about their willingness to receive the ChAd0x1 nCoV-19 vaccine, and $20.9 \%$ were willing to receive the RNA BNT162b2 vaccine. However, $18.3 \%$ reported that they would refuse to receive the Ad5vectored vaccine, and $17.9 \%$ would refuse the Gam-COVIDVac vaccine. Factors that influenced the differential readiness of HCWs included their perceptions of the vaccine's efficiency in preventing the infection (33\%), their personal preferences $(29 \%)$ and the vaccine's manufacturing country $(28.6 \%)$.

Conclusions Awareness by HCWs of the several COVID-19 candidate vaccines could improve their perceptions and acceptance of vaccination. Reliable sources on vaccine efficiency could improve vaccine uptake, so healthcare authorities should use reliable information to decrease vaccine hesitancy among frontline healthcare providers.
Strengths and limitations of this study

- The research is among the first studies to explore the perception, confidence, hesitancy and acceptance rates of various COVID-19 vaccine types among healthcare workers (HCWs).

- This is a national, cross-sectional survey among HCWs.

- The press release on the efficacy of the BNT162b2 vaccine coincided with ongoing data collection about the HCWs' willingness to vaccinate.

- Being a self-reported and survey-based study highlights that observational studies on the HCWs' actual acceptance of various COVID-19 vaccines are warranted in the nearest future.

- The convenience sample could limit the generalisability; therefore, further research is warranted.

\section{INTRODUCTION}

The COVID-19 pandemic has severely disrupted normal societal and economic activities worldwide and is expected to continue imposing strains and burden on health systems in most of countries. Globally, the COVID-19 pandemic remains out of control. ${ }^{1}$ The existing measures to control COVID-19 are detrimental to the global economy ${ }^{2}$ and result in significant impairment in physical and psychological well-being. ${ }^{3}$ To keep COVID-19 under control, there is a strong need for an effective vaccine. Without COVID-19 vaccination, healthcare workers (HCWs) will likely be at risk and are likely to serve as reservoir inside health institutes, which would undermine efforts to end the pandemic. According to the $\mathrm{WHO}$, there are 56 and 166 candidate vaccines in clinical and preclinical evaluation by 17 December $2020 .^{4}$ 
These include JNJ-78436735, an adenovirus vaccine (Ad26. COV2.S) $;{ }^{5}$ mRNA-1273, an mRNA vaccine; ${ }^{7}$ AZD1222, an adenovirus vaccine $(\mathrm{ChAdOx} 1 \mathrm{nCoV}-19) ;{ }^{8}$ BNT162b1, an mRNA vaccine; ${ }^{9}$ NVX-CoV2373, a full-length recombinant SARS-CoV-2 glycoprotein nanoparticle vaccine adjuvanted with Matrix $\mathrm{M}^{10}$ Ad5-nCoV, an adenovirus vaccine. ${ }^{11-14}$ Encouraging news is that several vaccines had been released and many are in phase III clinical trials and showing promising effectiveness. ${ }^{15}$ As some safe and efficacious vaccines became available, policymakers need to ensure a successful large-scale uptake of COVID-19 vaccines to achieve community immunisation. However, the success of COVID-19 vaccination programmes will largely depend on people's acceptance of the vaccine. A recent global survey suggested that nearly $30 \%$ of participants would be hesitated to take a COVID-19 vaccine when it is available. ${ }^{16}$ A systematic review on acceptance of a COVID-19 vaccine based on nationally representative surveys in 20 nations indicates that vaccine acceptance rate in most nations would not reach $67 \%$ that is necessary for achieving population immunity. ${ }^{17}$ Mathematic modelling suggested that if a COVID-19 vaccine efficacy was $80 \%$, the coverage must achieve at least $75 \%$ to extinguish the ongoing pandemic. ${ }^{18}$ Therefore, a timely understanding of community responses to the forthcoming COVID-19 vaccines would be important for policymaking and service planning.

Extant literature has explored vaccine acceptance and identified a few demographic and psychosocial correlates such as gender, age, trust in research, knowledge, and concerns about the novel vaccine, as well as people's judgement and perceptions regarding risk of COVID-19. ${ }^{19-21}$ Risk exposure to the disease is one of several essential issues that directly shape people's assessment to their vulnerability and risk. Even being weaponed with personal protective equipment, healthcare providers and other essential workers are considered to have high risk exposures to COVID-19 and given priority in vaccine allocations. Several studies suggest that being an HCW or being involved in the care of patients with COVID-19 is positively associated with COVID-19 vaccine acceptance. $^{22-24}$

The lessons learnt from previous infectious disease pandemics and outbreaks, including SARS, H1N1, Middle East respiratory syndrome coronavirus (MERS-CoV) and Ebola demonstrate the important role that health information has on disease control and vaccine acceptance. ${ }^{25}$ Source of health information can affect the manner and frequency of the utilisation of such information. The degree to which the information source is trusted can have a remarkable impact on the acceptance of information. ${ }^{26}$ If HCWs distrust the source, they will doubt the information regarding different COVID-19 vaccines, and this doubt will in turn shape their attitudes, perceptions and potential actions they take toward various COVID-19 vaccines.

The Kingdom of Saudi Arabia (KSA) is one of the top 30 countries with the highest reported COVID-19 cases:
360690 laboratory-confirmed cases and 6101 deaths as of 19 December 2020. ${ }^{27}$ Acceptance of a potential COVID-19 vaccine assessed among HCWs in KSA in a survey of 2007 participants showed an acceptance rate of $70 \%,{ }^{28}$ which is slightly higher than the acceptance rate found in public survey among 992 participants of general population (acceptance rate of $65 \%$ ) ${ }^{29}$ Perception, confidence, and hesitancy for various COVID-19 vaccines in the context of emerging viral infections and pandemics and manufacturing company and the different sources of information are principal factors in assessing vaccine acceptance of various types. To the best of our knowledge, none of published surveys specifically targeted and compared HCWs' perception, confidence and hesitancy toward different types of COVID-19 candidate vaccines. While our previous research showed that most $(70 \%)$ HCWs are willing to receive COVID-19 vaccines once available ${ }^{28}$ we aimed in this study to compare the perception, confidence, hesitancy and acceptance rate of various COVID-19 vaccine types among HCWs.

\section{METHODS}

\section{Data collection}

This study was a national cross-sectional survey among HCWs in Saudi Arabia during COVID-19 pandemic. Data were collected during 4-14 November 2020. At the time of data collection, at least seven COVID-19 vaccine candidates had been reported in the scientific literature. HCWs were screened for their awareness of any of the seven published vaccines. ${ }^{28}$ Participants were invited using a convenience sampling technique. We used several social media platforms and email lists to recruit participants for direct invitation. The survey was a pilot-validated, selfadministered questionnaire that was sent to HCWs online through SurveyMonkey, a platform that allows researchers to deploy and analyse surveys via the internet. ${ }^{30}$ This was an English questionnaire (as invited participants were multinational and all were English speakers) (online supplemental appendix 1$)^{31}$ with modifications and additions related to the potential COVID-19 vaccine.

The questions included the demographic characteristics of respondents (job category, age, sex, years of clinical experience and work area), and any previous exposure to MERS-CoV or to patients with COVID-19 (either suspected or confirmed). We assessed the following outcomes related to the seven COVID-19 vaccine candidates that had been reported in the scientific literature: knowledge, perceived awareness and readiness to receive each type of COVID-19 vaccine candidate. In addition, we assessed factors affecting respondents' readiness to receive various COVID-19 vaccine candidates and the HCW's sources of information about COVID-19 vaccines.

Before participation, the purpose of the study was explained in English at the beginning of the online survey. The respondent was given the opportunity to ask questions via a dedicated email address. A waiver for signed consent was obtained because the survey presented no 
more than a minimal risk to participants and involved no procedures for which written consent is usually required outside the study context. To maximise confidentiality, personal identifiers were not required.

HCWs were screened for their awareness of any of the seven published vaccines. Notably, Pfizer announced during the study that the efficacy of their vaccine in the first interim analysis was more than $90 \% .^{32}$

\section{Patient and public involvement}

While this study did not have a direct patient or public involvement, its aim was directed at the HCWs' perceptions about the acceptance of COVID-19 vaccines. However, these HCWs are in the frontline of the pandemic, serving to save the lives of thousands of patients worldwide. Therefore, safeguarding HCWs becomes among healthcare and patients' priorities. No patients were directly involved in this research. The results of the study were published as a preprint that was shared with study participants.

\section{Statistical analysis}

Descriptive statistics approaches, with means and SDs, were applied to continuous variables, and percentages were used for dichotomous variables. The two-sample t-test was used to evaluate continuous scores, and the $\mathrm{Z}$ test was used to compare proportions.

A multivariable logistic regression model was used to explore associations between the outcome variable of HCW knowledge about the available COVID-19 vaccine candidates and HCW demographic, belief toward vaccine candidates, and level of anxiety. The association between predictors and the outcome was expressed as the OR and 95\% CI. SPSS (V.21; IBM Corp) was used for the data analysis, Excel (Microsoft) was used for creating figures and depictions, and statistical significance was set at $\mathrm{p}=0.050{ }^{33}$

\section{RESULTS}

A total of 2007 HCWs agreed to participate, and 1512 participants $(75.3 \%)$ completed the survey and were included in the analysis. Almost quarter of respondents did not complete the survey and were excluded from analysis. The participants' sociodemographic characteristics are shown in table 1.

Women comprised most of the population (62.4\%), most participants $(70.3 \%)$ were between 21 and 40 years of age, $68.6 \%$ were married-though only $47.3 \%$ were living with their families-and $76.2 \%$ reported not having any chronic illnesses.

Respondents' working areas were distributed almost evenly across different sectors of health institutions, but the majority were from the public/governmental (47.1\%) sectors and tertiary institutions (62.2\%). In terms of awareness of potential vaccine candidates reported in the literature, the majority $(59.5 \%)$ reported knowing about at least one vaccine.
Table 1 Respondents' sociodemographic and professional characteristics $(\mathrm{N}=1512)$

\begin{tabular}{lc}
\hline Characteristic & N (\%) \\
\hline Sex & \\
\hline Male & $568(37.6)$ \\
\hline Female & $944(62.4)$ \\
\hline Age (years), mean (SD) & $37.28(8.99)$ \\
\hline $21-30$ & $385(25.5)$ \\
\hline $31-40$ & $677(44.8)$ \\
\hline $41-50$ & $298(19.7)$ \\
\hline 250 & $152(10.1)$ \\
\hline Marital status & \\
\hline Single & $435(28.8)$ \\
\hline Married, living with family & $715(47.3)$ \\
\hline Married, living alone & $322(21.3)$ \\
\hline Widowed or divorced & $40(2.6)$ \\
\hline Any chronic illness & \\
\hline No & $1152(76.2)$ \\
\hline Yes & $360(23.8)$ \\
\hline Clinical role & \\
\hline Physician & $637(42.1)$ \\
\hline Nurse & $757(50.1)$ \\
\hline Other healthcare providers & $118(7.8)$ \\
\hline Working area & \\
\hline Intensive care unit: adults and \\
paediatrics
\end{tabular}

*Other healthcare providers include technicians, respiratory therapists and pharmacists.

The ChAdOx1 nCoV-19 vaccine was the vaccine recognised the most by HCWs (39.3\%), followed by the Gam-COVID-Vac vaccine $(31.9 \%)$ and the RNA BNT162b2 vaccine $(30.8 \%)$. The least well-known vaccine 
Table 2 Perceived awareness of and readiness to receive various COVID-19 vaccine candidates by healthcare workers

\begin{tabular}{|c|c|c|c|c|}
\hline \multirow[b]{2}{*}{ Vaccine candidate } & \multirow{2}{*}{$\begin{array}{l}\text { No }(\%) \text { knows } \\
\text { about vaccine* }\end{array}$} & \multicolumn{3}{|c|}{ No (\%) willingness to take the vaccine } \\
\hline & & Never & Maybe & Sure \\
\hline $\begin{array}{l}\text { AstraZeneca (Oxford University: British/Swedish) non-replicating viral } \\
\text { vector (chimpanzee adenovirus vectored vaccine (ChAdOx1 nCoV-19) }\end{array}$ & $594(39.3)$ & $159(10.5)$ & $984(65.1)$ & $369(24.4)$ \\
\hline $\begin{array}{l}\text { Gamaleya (Russia)-Sputnik V non-replicating viral vector adenovirus } \\
\text { (Gam-COVID-Vac) }\end{array}$ & $482(31.9)$ & $271(17.9)$ & $1100(72.8)$ & $141(9.3)$ \\
\hline $\begin{array}{l}\text { Pfizer RNA (BNT162b2; USA): nucleoside-modified messenger RNA } \\
\text { (modRNA) }\end{array}$ & $466(30.8)$ & $154(10.2)$ & $1042(68.9)$ & $316(20.9)$ \\
\hline CanSino (China; adenovirus type 5; Ad5-vectored) & $397(26.3)$ & $277(18.3)$ & $1103(72.3)$ & $132(8.7)$ \\
\hline $\begin{array}{l}\text { Novavax (USA) protein subunit (full-length recombinant SARS CoV-2 } \\
\text { glycoprotein nanoparticle vaccine adjuvanted with Matrix M; NVX- } \\
\text { CoV2373) }\end{array}$ & $364(24.1)$ & $166(11)$ & $1139(75.3)$ & $208(13.8)$ \\
\hline Moderna RNA (USA; mRNA-1273) & 301 (19.9) & $170(11.2)$ & $1142(75.5)$ & 200 (13.2) \\
\hline
\end{tabular}

*Percentage expressed of total sample ( $\mathrm{N}=1512$ healthcare workers).

among HCWs was the mRNA-1273 vaccine $(19.9 \%$; table 2).

HCWs were asked to indicate their readiness to receive each type of COVID-19 vaccine with response categories of 'never, maybe or sure' (ie, willing to receive). The respondents reported 'maybe' in $(65.1 \%)$ for the (AstraZeneca) vaccine and up to $(75.5 \%)$ for the (Moderna), while they were 'sure' to receive the vaccine if it was (CanSino) in $(9.3 \%)$ but up to $(24.4 \%)$ if the (AstraZeneca) one, on the other hand they answered 'never receive' for the (Johnson and Johnson) or (Pfizer) vaccines in (10.2\%) but up to $(18.3 \%)$ for the (CanSino) (table 2).

In determining factors influencing differential readiness of HCWs to receive vaccine candidates, a multipleresponse dichotomies analysis showed that respondents' perception of the vaccine candidate as being more efficient in preventing infection was the most influencing factor $(33 \%)$ in their decisions, followed by their personal preferences $(29 \%)$ and the vaccine's manufacturing country $(28.6 \%)$. The least influential factors were media and social media coverage $(12.3 \%)$ and trustworthiness (4.2\%; table 3$)$.

Table 3 Factors affecting respondents' readiness to receive COVID-19 vaccine candidates $(\mathrm{N}=1512)$

\begin{tabular}{ll}
\hline & N (\%) \\
\hline $\begin{array}{l}\text { This COVID-19 vaccine(s) seems more } \\
\text { efficient in preventing the infection }\end{array}$ & $499(33)$ \\
Personal preference & $439(29)$ \\
Manufacturing country & $433(28.6)$ \\
$\begin{array}{l}\text { Possibly fewer adverse effects from this } \\
\text { vaccine }\end{array}$ & $417(27.6)$ \\
Vaccine availability & $394(26.1)$ \\
Company's reputation & $395(26.1)$ \\
Media coverage & $186(12.3)$ \\
\hline Trustworthiness & $64(4.2)$ \\
\hline
\end{tabular}

The HCW's sources of information about COVID-19 vaccines are shown in table 4 . The WHO website was the most used source for information $(51.1 \%)$, followed by social media networks $(48.3 \%)$, the Saudi Ministry of Health $(\mathrm{MOH})$ website $(43.8 \%)$ and official press releases $(38.3 \%)$. The Centers for Disease Control and Prevention website was used by only one-third of participants (table 4).

A substantial number of HCWs in this study $(n=612$, $40.5 \%$ ) reported unawareness of some vaccine candidates reported in scientific literature as of the time of the study. Therefore, as a secondary analysis, the generalised linear multivariate gamma regression analysis was used to explain the predictors of how likely the surveyed HCWs were to be aware of the different scientifically reported vaccine candidates. These results are presented in table 5 and show that women knew significantly less than men about the different vaccine candidates $(\mathrm{p}=0.016)$. Older age correlated significantly and positively with more knowledge $(p=0.027)$. Also, physicians knew significantly

Table 4 Respondents' sources of information about COVID-19 vaccine types $(\mathrm{N}=1490)$

\begin{tabular}{ll} 
& N (\%) \\
\hline WHO website & $762(51.1)$ \\
$\begin{array}{l}\text { Social networks (eg, YouTube, Facebook, } \\
\text { Twitter, WhatsApp) }\end{array}$ & $719(48.3)$ \\
$\begin{array}{l}\text { MOH website } \\
\text { Official statements or press releases from }\end{array}$ & $570(43.8)$ \\
$\begin{array}{l}\text { MOH (eg, through SMS or newspapers) } \\
\text { Hospital announcements (eg, roll-ups or }\end{array}$ & $543(36.4)$ \\
newsletters) & $537(36.0)$ \\
$\begin{array}{l}\text { Other internet resources } \\
\text { CDC website }\end{array}$ & $501(33.6)$ \\
\hline
\end{tabular}

$\mathrm{CDC}$, Centres for Disease Control and Prevention; $\mathrm{MOH}$, Ministry of Health; SMS, short message service. 
Table 5 Generalised linear modelling analysis of the healthcare workers' knowledge of the available COVID-19 vaccine candidates

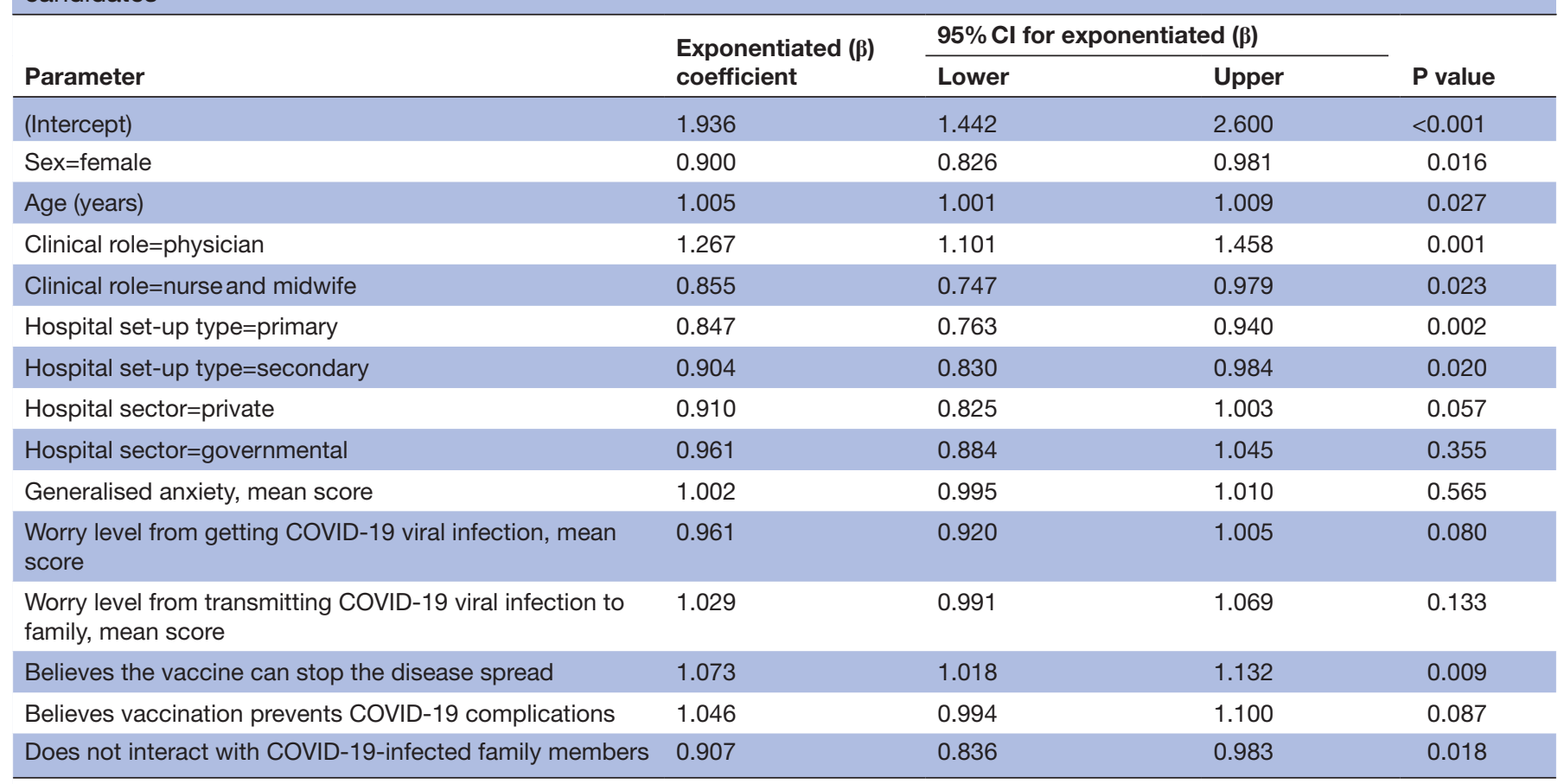

Dependent variable was the total number of vaccines the healthcare workers knew about. The exponentiated $(\beta)$ coefficient was interpreted as a rate.

more about vaccine candidates than other HCWs did $(\mathrm{p}=0.001)$, and the HCWs from primary and secondary health centres knew of significantly fewer COVID-19 vaccine candidates than did HCWs from tertiary medical centres $(\mathrm{p}=0.002$ for primary, $\mathrm{p}=0.02$ for secondary). The participant's belief in the ability of COVID-19 vaccines to stop the pandemic predicted significantly higher knowledge of the available vaccine candidates $(\mathrm{p}=0.009)$. HCWs who did not interact with COVID-19-infected family members knew significantly less about the available vaccine candidates $(\mathrm{p}=0.018)$. Other specific worry/ anxiety levels and beliefs were assessed, as reported in table 5 .

Our analysis (figure 1) showed a significantly higher percentage rate of HCW readiness to receive any COVID-19 vaccine relative to the refusal rate after the Pfizer announcement compared with before it $\left(\chi^{2}(1) 4.56\right.$, $\mathrm{p}=0.032$ ). In addition, the percentage of HCWs accepting

\section{Readiness to take COVID-19 vaccines}

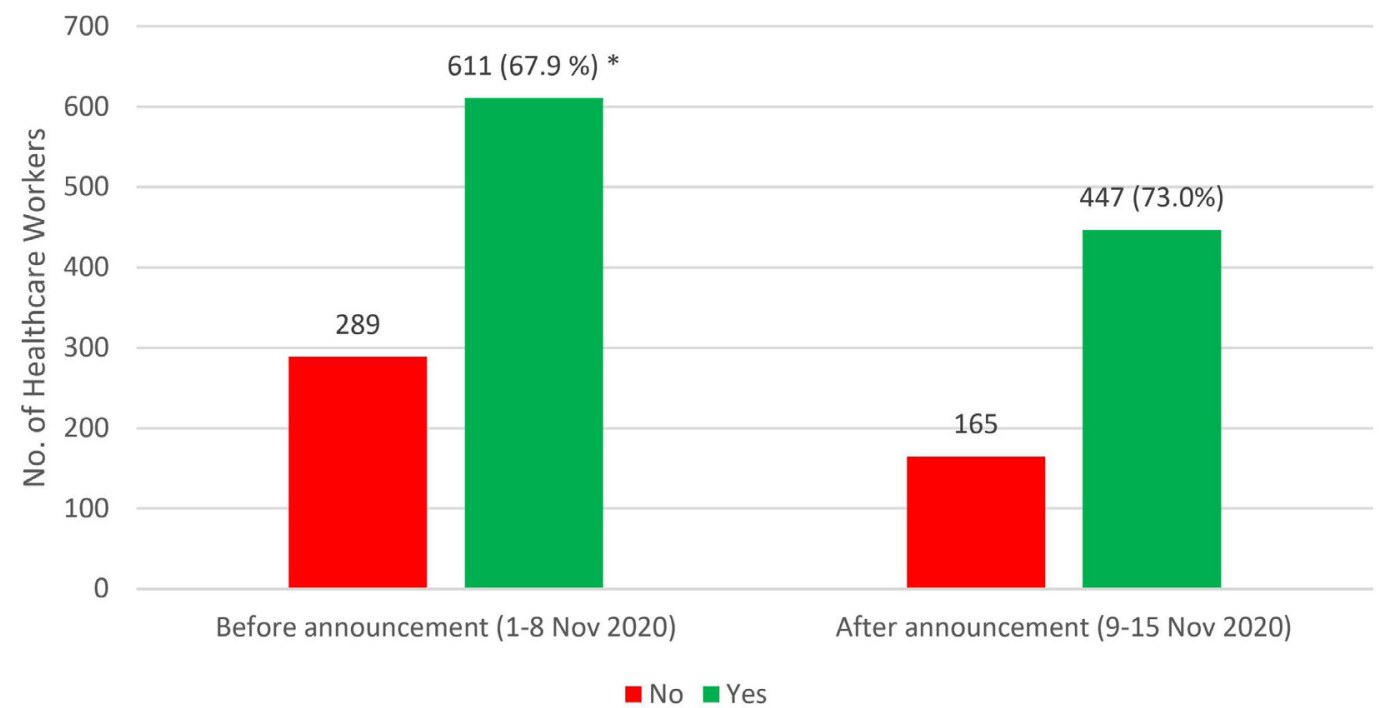

Figure 1 Readiness to take COVID-19 vaccines, as reported before and after the interim report of the efficacy rate of BNT162b2. ${ }^{*} \mathrm{P}=0.032$. 


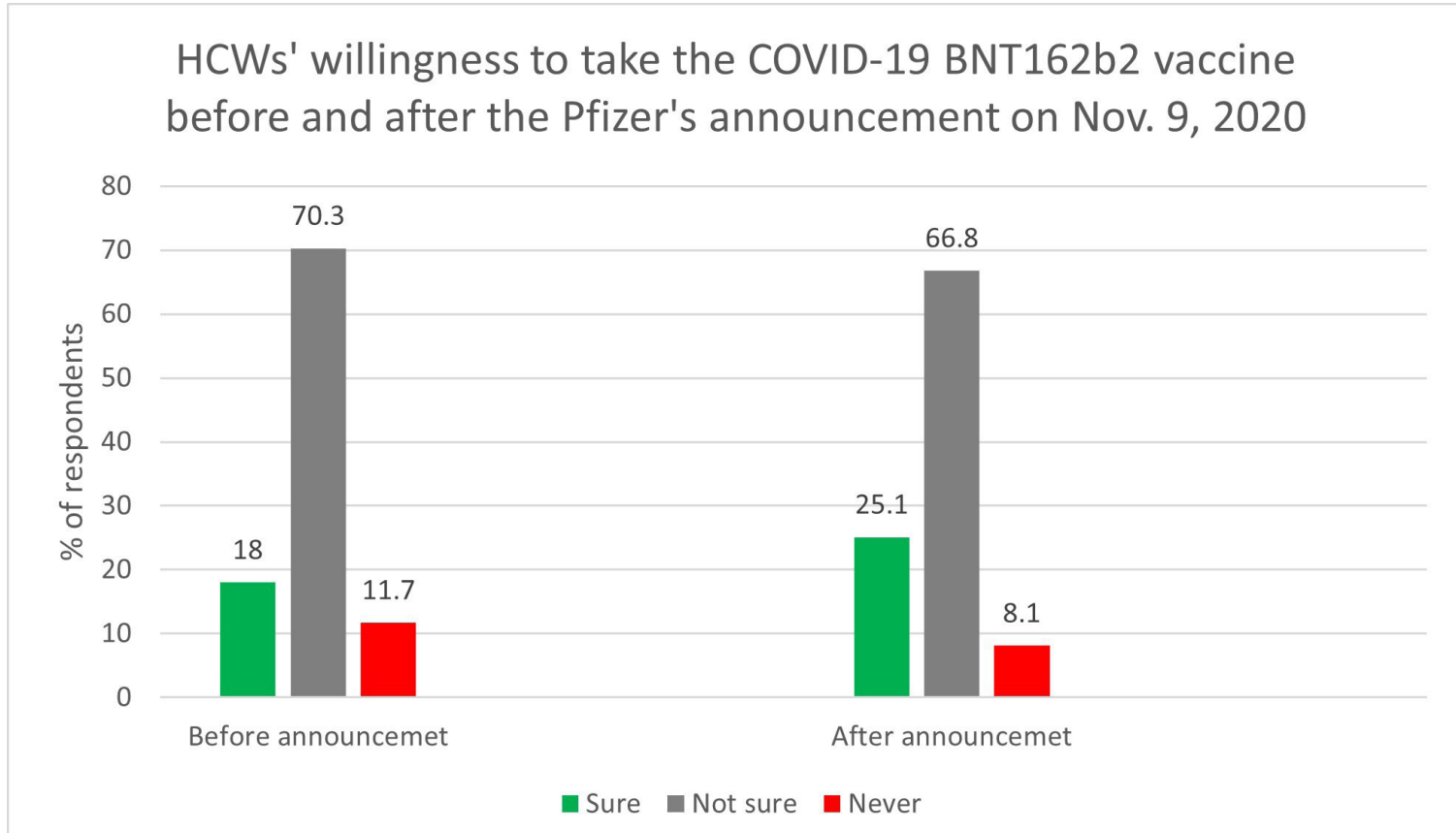

Figure 2 The percentage of healthcare workers (HCWs) willing to receive the BNT162b2 vaccine after its efficacy announcement.

to take the BNT162b2 vaccine increased from $18 \%$ to $25.1 \%$, and proportion of those who stated they will never take the BNT162b2 vaccine dropped from $12 \%$ to $8.1 \%$ following Pfizer's announcement (figure 2).

\section{DISCUSSION}

Since the beginning of the pandemic, an unprecedented global effort to develop a vaccine has been underway; research and development of different technologies have been applied for different vaccine candidates. The effort resulted in several types of vaccine candidates developed with various technologies, including adenovirus and RNA-based vaccines, all of which are novel and have not been developed for wide clinical use in other infectious diseases. Gaining knowledge of such new vaccines, with the rapid evolution of the development process, may be challenging: only $40 \%$ of study participants were aware of the ChAdOx1 nCoV-19 vaccine,,$^{5-9113435}$ and only onethird were aware of the BNT162b2, Gam-COVID-Vac and Ad26.COV2-S vaccines. Only a quarter of participants knew about the remaining vaccines. To our knowledge, data about HCW knowledge of vaccine candidates have not been published elsewhere.

The acceptance rate of COVID-19 vaccines is variable. In a global survey in 19 countries about the potential acceptance of a COVID-19 vaccine among the public, $71.5 \%$ reported they would very or somewhat likely agree to receive a vaccine; respondents from China gave the highest proportion of positive responses $(631$ (88.6\%) of 712 respondents) and the lowest proportion of negative responses $(5(0.7 \%)$ of 712$)$ when asked if they would take a proven, safe and effective vaccine. Respondents from Poland reported the highest proportion of negative responses (182 (27.3\%) of 666), whereas Russian respondents gave the lowest proportion of positive responses (373 $(54.9 \%)$ of 680$)$. Data are available about other diseases with multiple vaccine types as well. In a parental survey on acceptance of an intranasal, live, attenuated influenza vaccine, $81 \%$ preferred this version compared with the injectable inactivated influenza vaccine. ${ }^{36}$ During the H1N1 pandemic, 50 of $161 \mathrm{HCWs}(31.1 \%)$ were willing to take the $2009 \mathrm{H} 1 \mathrm{~N} 1$ vaccine. ${ }^{37}$ In a cross-sectional survey conducted in Riyadh in 2019 on influenza vaccine uptake, results showed an acceptance rate of $71 \%$ with hesitancy attributed to concerns on adverse events in $50 \%$ of participants. ${ }^{38}$ It was also noted that people in the Middle East generally have low acceptance rate of COVID-19 vaccines and such acceptance was 23\%-66\%. ${ }^{29} 3940$ However, no such acceptance rate has been evaluated among HCWs. ${ }^{41}$

It is interesting to note that, of all the HCW respondents asked about taking a COVID-19 vaccine, only $20 \%$ or $24 \%$ preferred to receive the AstraZeneca or the Pfizer vaccine, respectively. This low response to acceptance of any vaccine in development may indicate variability in the knowledge and understanding about the different vaccines. Vaccine knowledge is an area that needs more study to understand variables contributing to acceptance or rejection of each type of vaccine according to different development platforms used. This understanding would aid policymakers in the development of appropriate educational materials to boost confidence in various vaccine platforms.

Many factors affect the choice to receive vaccines. In this study, the top reason for choosing a vaccine was that 
the vaccine seems more effective at preventing infection $(33 \%)$. A previous study found that $50 \%$ vaccine efficacy was associated with a $51 \%$ rate of acceptance. ${ }^{42}$

The manufacturing country was another reason given for accepting the vaccine (in $28.6 \%$ of respondents). This finding is similar to results from a US survey related to hypothetical vaccines. The surveyed individuals had lower acceptance of the vaccine if it originated from a country outside the USA. ${ }^{42}$ Other contributing factors, such as fewer adverse effects, were also reported in this study. ${ }^{42}$ Understanding these factors is important to build strategies for vaccine acceptance in any community. Strategies should address concerns, contributing factors and misconceptions. ${ }^{43}$ Trustworthiness was indicated by approximately $4 \%$ of the respondents as a factor in accepting a COVID-19 vaccine. This is quite different when compared with the general population in the USA, in which trust and perceptions of local COVID-19 vaccination norms were the strongest predictors of COVID-19 vaccine acceptance. ${ }^{44}$ The difference might be the fact that our study included only HCWs who may have better understanding of the disease and the vaccination. It is important to note that trust is an important modifiable element of any successful vaccine campaign. Trustworthiness was strongly associated with acceptance of a COVID-19 vaccine, ${ }^{45}$ and this factor was also related to acceptance of other vaccines, such as H1N1, SARS and MERS-CoV vaccines. ${ }^{25}$

The most-reported sources of information for HCWs were the WHO website and social networks (as expected in a pandemic). Previously, Alsubaie et $a t^{46}$ reported results from the same HCW population, which showed that hospital announcements and MOH official statements were more commonly sought for information about the MERS-CoV national outbreak. In the case of the general public, the source of knowledge and information about COVID-19 was official government social media and Twitter. ${ }^{47}$ And another study showed $85.8 \%$ of the public in Saudi Arabia used the internet and social media for information regarding COVID-19. In a study from the USA, $45 \%-66 \%$ of HCWs used social media as a source of information. ${ }^{48}$ These findings suggest that HCWs in Saudi Arabia use social networking sites differently than their US counterparts, which is important for other studies that look at social media and knowledge. Seeking knowledge from reliable sources about the pandemic and vaccinations could significantly impact the HCWs' perceptions of vaccine acceptance. ${ }^{50}$ Misinformation about the COVID-19 vaccine was associated with decreased vaccination acceptance among those who would otherwise definitely vaccinate. ${ }^{51}$

It is interesting to note the differences in knowledge about vaccines by level of training. Physicians knew significantly more about vaccine candidates than other HCWs did $(\mathrm{p}=0.001)$ (table 5). Similarly, in a study from the USA, general COVID-19 knowledge among physicians was higher than other HCW, but non-physicians who work in healthcare did not have greater knowledge than the public. ${ }^{49}$ Noteworthy, HCWs working in tertiary and academic centres were more knowledgeable about various vaccine candidates compared with HCWs working in primary and secondary centres. This result may be explained by more scientific activity and educational campaigns typically associated with teaching hospitals. This increased knowledge was especially common among physicians in our study, like other studies; in a crosssectional survey conducted in Italy among HCWs to assess their knowledge, attitudes, and practices about vaccinations, physicians and those who had received information about vaccinations from scientific journals, educational activities, or professional associations were more likely to have adequate knowledge. ${ }^{52}$ The knowledge differences identified between centres and types of providers highlight the importance of academic activities and keeping up to date with the scientific literature during the COVID-19 pandemic.

Remarkably, after the Pfizer and BioNTech announcement about the efficacy rate of BNT162b2, the HCWs in our study demonstrated significantly more willingness to undergo vaccination. ${ }^{32}$ This change was despite simultaneous negative news on some COVID-19 vaccination trials, such as the halting of clinical studies with the CoronaVac vaccine by the Brazilian national sanitary regulator (Anvisa) due to a serious adverse event. ${ }^{53}$ Vaccine acceptance is a multifactorial issue, but having positive COVID-19 vaccine trial results circulating in the news and social media for several days after the press release on the efficacy of BNT162b2 could improve the HCWs' willingness to vaccinate.

This study has the limitation of being self-reported and survey based, so future observational studies on the HCWs' actual acceptance of various COVID-19 vaccines are warranted. As a cross-sectional survey promoted on social media, it is not possible to calculate a response rate, and results may not be generalisable over time; therefore, further research is warranted. Another aspect is the national design that needs further research for external validity in other countries.

\section{CONCLUSION}

HCW awareness of the several COVID-19 candidate vaccines could improve perception and acceptance of vaccination. Reliable sources on vaccine efficiency could improve vaccine uptake, and healthcare authorities should use these sources to decrease vaccine hesitancy among frontline healthcare providers.

\section{Author affiliations}

${ }^{1}$ College of Medicine, King Saud University, Riyadh, Saudi Arabia

${ }^{2}$ Pediatric Department, King Saud University Medical City, Riyadh, Saudi Arabia ${ }^{3}$ Department of Internal Medicine, King Saud University Medical City, Riyadh, Saudi Arabia

${ }^{4}$ Critical Care Department, King Saud University Medical City, Riyadh, Saudi Arabia ${ }^{5}$ Cardiac Science Department, King Saud University Medical City, Riyadh, Saudi Arabia

${ }^{6}$ Sharjah Institute for Medical Research, University of Sharjah, Sharjah, UAE 
${ }^{7}$ College of Medicine, University of Sharjah, Sharjah, UAE

${ }^{8}$ Department of Medicine, Qassim University, Buraidah, Saudi Arabia

${ }^{9}$ Dr.Suliman Alhabib Medical Group, Riyadh, Saudi Arabia

${ }^{10}$ Department of Family and Community Medicine, King Saud University Medical City, Riyadh, Saudi Arabia

${ }^{11}$ Evidence-Based Health Care \& Knowledge Translation Research Chair, King Saud University, Riyadh, Saudi Arabia

${ }^{12}$ King Saud Medical City, Ministry of Health \& Alfaisal University, Riyadh, Saudi Arabia

${ }^{13}$ Hubert Department of Global Health, Emory University Atlanta, Atlanta, Georgia, USA

${ }^{14}$ Specialty Internal Medicine and Quality Department, Johns Hopkins Aramco Healthcare, Dhahran, Saudi Arabia

${ }^{15}$ Infectious Disease Division, Department of Medicine, Indiana University School of

Medicine, Indianapolis, Indiana, USA

${ }^{16}$ Infectious Disease Division, Department of Medicine, Johns Hopkins University School of Medicine, Baltimore, Maryland, USA

Acknowledgements We thank all the healthcare workers who participated in this survey and all those in the COVID-19 front lines. We also thank hodhodata.com for their statistical analysis and support.

Contributors M-HT, MB, JAA-T, ZAM and FAlsohime were involved in conception, analysed the data and wrote the manuscript. AAlhuzaimi, AA-E, FAljamaan, BS, AAlrabiaah and NMA contributed to the study design; collected, analysed and interpreted data; and edited the manuscript. AAlhuzaimi, FSA-S, KA, AAlrabiaah, AAlaraj, AAlhaboob and SA supervised data collection, analysed data and edited the manuscript. $A A-E, R H$ and $A J$ interpreted the data and wrote the manuscript. All authors reviewed and approved the final version of the manuscript.

Funding The authors are grateful to the Deanship of Scientific Research, King Saud University, for funding through the Vice Deanship of Scientific Research Chairs. Award/grant number is not applicable.

Competing interests None declared.

Patient consent for publication Not required.

Ethics approval The institutional review board at the College of Medicine and King Saud University Medical City approved the study (approval \#20/0065/IRB).

Provenance and peer review Not commissioned; externally peer reviewed.

Data availability statement Data are available upon reasonable request.

Supplemental material This content has been supplied by the author(s). It has not been vetted by BMJ Publishing Group Limited (BMJ) and may not have been peer-reviewed. Any opinions or recommendations discussed are solely those of the author(s) and are not endorsed by BMJ. BMJ disclaims all liability and responsibility arising from any reliance placed on the content. Where the content includes any translated material, BMJ does not warrant the accuracy and reliability of the translations (including but not limited to local regulations, clinical guidelines, terminology, drug names and drug dosages), and is not responsible for any error and/or omissions arising from translation and adaptation or otherwise.

Open access This is an open access article distributed in accordance with the Creative Commons Attribution Non Commercial (CC BY-NC 4.0) license, which permits others to distribute, remix, adapt, build upon this work non-commercially, and license their derivative works on different terms, provided the original work is properly cited, appropriate credit is given, any changes made indicated, and the use is non-commercial. See: http://creativecommons.org/licenses/by-nc/4.0/.

\section{ORCID iDs}

Mohamad-Hani Temsah http://orcid.org/0000-0002-4389-9322

Mazin Barry http://orcid.org/0000-0003-2274-007X

Fadi Aljamaan http://orcid.org/0000-0001-8404-6652

Ayman Al-Eyadhy http://orcid.org/0000-0002-6051-9125

Basema Saddik http://orcid.org/0000-0002-4682-5927

Fahad Alsohime http://orcid.org/0000-0002-4979-3895

Ali Alhaboob http://orcid.org/0000-0003-2126-7874

Khalid Alhasan http://orcid.org/0000-0002-4291-8536

Ali Alaraj http://orcid.org/0000-0002-7706-2328

Rabih Halwani http://orcid.org/0000-0002-6516-7771

Nurah Maziad Alamro http://orcid.org/0000-0001-9489-3994

Amr Jamal http://orcid.org/0000-0002-4051-6592

Ziad A Memish http://orcid.org/0000-0002-5099-0714
Jaffar A Al-Tawfiq http://orcid.org/0000-0002-5752-2235

\section{REFERENCES}

1 World Health Organization. Coronavirus disease 2019 (COVID-19) situation report - 71. Available: https://www.who.int/docs/defaultsource/coronaviruse/situation-reports/20200331-sitrep-71-covid-19. pdf [Accessed 27 Apr 2020]

2 The State Council the People's Republic of China. COVID-19 sends most G20 members into negative GDP growth, except China. Available: http://english.www.gov.cn/news/topnews/202009/05/ content_WS5f5398c8c6d0f7257693b957.html [Accessed 15 Dec 2020].

3 CarvalhoAguiarMeloM, de Sousa Soares D. Impact of social distancing on mental health during the COVID-19 pandemic: an urgent discussion. Int J Soc Psychiatry 2020;6.

4 WHO. Draft landscape of COVID-19 candidate vaccines. Available: https://www.who.int/publications/m/item/draft-landscape-of-covid19-candidate-vaccines [Accessed 19 Dec 2020].

5 A study of Ad26.COV2.S for the prevention of SARS-CoV-2Mediated COVID-19 in adult participants (ensemble). Available: https://clinicaltrials.gov/ct2/show/NCT04505722 [Accessed 2 Dec 2020].

6 Mullard A. COVID-19 vaccine development pipeline gears up. Lancet 2020;395:1751-2.

7 Anderson EJ, Rouphael NG, Widge AT, et al. Safety and immunogenicity of SARS-CoV-2 mRNA-1273 vaccine in older adults. N Engl J Med 2020;383:2427-38.

8 Folegatti PM, Ewer KJ, Aley PK, et al. Safety and immunogenicity of the ChAdOx1 $\mathrm{nCoV}-19$ vaccine against SARS-CoV-2: a preliminary report of a phase $1 / 2$, single-blind, randomised controlled trial. Lancet 2020;396:467-78.

9 Walsh EE, Frenck RW, Falsey AR, et al. Safety and immunogenicity of two RNA-based Covid-19 vaccine candidates. N Engl J Med 2020;383:2439-50.

10 Keech C, Albert G, Cho I, et al. Phase 1-2 trial of a SARS-CoV-2 recombinant spike protein nanoparticle vaccine. N Engl J Med 2020;383:2320-32.

11 Zhu F-C, Guan X-H, Li Y-H, et al. Immunogenicity and safety of a recombinant adenovirus type-5-vectored COVID-19 vaccine in healthy adults aged 18 years or older: a randomised, double-blind, placebo-controlled, phase 2 trial. Lancet 2020;396:479-88.

12 Bar-Zeev N, Moss WJ. Encouraging results from phase 1/2 COVID-19 vaccine trials. Lancet 2020;396:448-9.

13 Zhu F-C, Li Y-H, Guan X-H, et al. Safety, tolerability, and immunogenicity of a recombinant adenovirus type- 5 vectored COVID-19 vaccine: a dose-escalation, open-label, non-randomised, first-in-human trial. Lancet 2020;395:1845-54.

14 Gao Q, Bao L, Mao H, et al. Development of an inactivated vaccine candidate for SARS-CoV-2. Science 2020;369:77-81.

$15 \mathrm{NIH}$. National Institute of Health. Promising interim results from clinical trial of NIH-Moderna COVID-19 vaccine. Available: https:// www.nih.gov/news-events/news-releases/promising-interim-resultsclinical-trial-nih-moderna-covid-19-vaccine [Accessed 15 Dec 2020]

16 Kwok KO, Lai F, Wei WI, et al. Herd immunity - estimating the level required to halt the COVID-19 epidemics in affected countries. $J$ Infect 2020;80:e32-3.

17 Feleszko W, Lewulis P, Czarnecki A. Flattening the curve of COVID-19 vaccine rejection-A global overview. SSRN, 2020

18 Bartsch SM, O'Shea KJ, Ferguson MC, et al. Vaccine efficacy needed for a COVID-19 coronavirus vaccine to prevent or stop an epidemic as the sole intervention. Am J Prev Med 2020;59:493-503.

19 Grech V, Gauci C, Agius S. Withdrawn: vaccine hesitancy among Maltese healthcare workers toward influenza and novel COVID-19 vaccination. Early Hum Dev 2020;105213:105213.

20 Palamenghi L, Barello S, Boccia S, et al. Mistrust in biomedical research and vaccine hesitancy: the forefront challenge in the battle against COVID-19 in Italy. Eur J Epidemiol 2020;35:785-8.

21 Wong LP, Alias H, Wong P-F, et al. The use of the health belief model to assess predictors of intent to receive the COVID-19 vaccine and willingness to pay. Hum Vaccin Immunother 2020;16:2204-14.

22 Detoc M, Bruel S, Frappe P, et al. Intention to participate in a COVID-19 vaccine clinical trial and to get vaccinated against COVID-19 in France during the pandemic. Vaccine 2020;38:7002-6.

23 Dror AA, Eisenbach N, Taiber S, et al. Vaccine hesitancy: the next challenge in the fight against COVID-19. Eur J Epidemiol 2020;35:775-9.

24 Wang K, Wong ELY, Ho KF, et al. Intention of nurses to accept coronavirus disease 2019 vaccination and change of intention to 
accept seasonal influenza vaccination during the coronavirus disease 2019 pandemic: a cross-sectional survey. Vaccine 2020;38:7049-56.

25 Siegrist M, Zingg A. The role of public trust during pandemics: implications for crisis communication. Eur Psychol 2014;19:23.

26 Freed GL, Clark SJ, Butchart AT, et al. Sources and perceived credibility of vaccine-safety information for parents. Pediatrics 2011:127 Suppl 1:S107-12.

27 Hopkins J M U. Coronavirus resource center. COVID-19 Map 2020 Available: https://coronavirus.jhu.edu/map.html [Accessed 19 Dec 2020].

28 Barry M, Temsah M-H, Alhuzaimi A. COVID-19 vaccine confidence and hesitancy among healthcare workers: a cross-sectional survey from a MERS-CoV experienced nation. medRxiv 2020.

29 Al-Mohaithef M, Padhi BK. Determinants of COVID-19 vaccine acceptance in Saudi Arabia: a web-based national survey. $J$ Multidiscip Healthc 2020;13:1657-63.

30 Regmi PR, Waithaka E, Paudyal A, et al. Guide to the design and application of online questionnaire surveys. Nepal J Epidemiol 2016;6:640-4.

31 Temsah MH, Alhuzaimi AN, Alamro N. Knowledge, attitudes, and practices of healthcare workers during the early COVID-19 pandemic in a main, academic tertiary care centre in Saudi Arabia. Epidemiol Infect 2020:1-29.

32 Pfizer and BIONTECH announce vaccine candidate against COVID-19 achieved success in first interim analysis from phase 3 study. Available: https://www.pfizer.com/news/press-release/press release-detail/pfizer-and-biontech-announce-vaccine-candidateagainst [Accessed 16 Dec 2020].

33 IBM Corp. Ibm SPSS statistics for windows. Armonk, NY: IBM Corp, 2012.

34 Schwartz JL. Evaluating and Deploying Covid-19 Vaccines - The Importance of Transparency, Scientific Integrity, and Public Trust. N Engl J Med 2020;383:1703-5

35 Bedford J, Enria D, Giesecke J, et al. COVID-19: towards controlling of a pandemic. Lancet 2020;395:1015-8.

36 Lazarus JV, Ratzan SC, Palayew A. A global survey of potential acceptance of a COVID-19 vaccine. Nat Med 2020:1-4.

37 Al-Tawfiq JA. Willingness of health care workers of various nationalities to accept H1N1 (2009) pandemic influenza A vaccination. Ann Saudi Med 2012;32:64-7.

38 Barry MA, Aljammaz KI, Alrashed AA. Knowledge, attitude, and barriers influencing seasonal influenza vaccination uptake. Can $J$ Infect Dis Med Microbiol 2020;2020:1-6.

39 Sallam M, Dababseh D, Eid H, et al. High rates of COVID-19 vaccine Hesitancy and its association with conspiracy beliefs: a study in Jordan and Kuwait among other Arab countries. Vaccines 2021;9. doi:10.3390/vaccines9010042. [Epub ahead of print: 1201 2021].

40 Salali GD, Uysal MS. COVID-19 vaccine hesitancy is associated with beliefs on the origin of the novel coronavirus in the UK and turkey. Psychol Med 2020:1-3.

41 Marien A-G, Hochart A, Lagrée M, et al. Parental acceptance of an intranasal vaccine: example of influenza vaccine. Arch Pediatr 2019;26:71-4.

42 Kreps S, Prasad S, Brownstein JS, et al. Factors associated with us adults' likelihood of accepting COVID-19 vaccination. JAMA Netw Open 2020;3:e2025594.

43 Biasio LR. Vaccine hesitancy and health literacy. Hum Vaccin Immunother 2017;13:701-2.

44 Lennon RP, Small ML, Smith RA. Unique predictors of intended uptake of a COVID-19 vaccine. medRxiv 2020.

45 Hovland $\mathrm{Cl}$, Weiss W. The influence of source credibility on communication effectiveness. Public Opin Q 1951;15:635-50.

46 Alsubaie S, Hani Temsah M, Al-Eyadhy AA, et al. Middle East respiratory syndrome coronavirus epidemic impact on healthcare workers' risk perceptions, work and personal lives. J Infect Dev Ctries 2019;13:920-6.

47 Alnasser AHA, Al-Tawfiq JA, Al Kalif MSH, et al. The positive impact of social media on the level of COVID-19 awareness in Saudi Arabia: a web-based cross-sectional survey. Infez Med 2020;28:545-50.

48 Alnasser AHA, Al-Tawfiq JA, Al-Kalif MSH, et al. Public knowledge, attitudes, and practice towards COVID-19 pandemic in Saudi Arabia: a web-based cross-sectional survey. Med Sci 2021;9. doi:10.3390/ medsci9010011. [Epub ahead of print: 16 Feb 2021].

49 Sathianathan S, Van Scoy LJ, Sakya SM, et al. Knowledge, perceptions, and preferred information sources related to COVID-19 among healthcare workers: results of a cross sectional survey. Am J Health Promot 2021;35:633-636.

50 Temsah M-H, Barry M, Aljamaan F. SARS-CoV-2 B. 1.1. 7 lineagerelated perceptions and travel worry among healthcare workers. medRxiv 2021.

51 Loomba S, de Figueiredo A, Piatek S. Measuring the impact of exposure to COVID-19 vaccine misinformation on vaccine intent in the UK and US. medRxiv 2020.

52 Pelullo CP, Della Polla G, Napolitano F. Attitudes, and practices about vaccinations: a cross-sectional study in Italy. Vaccines 2020;8:148.

53 Anvisa. Anvisa halts CoronaVac studies after "serious adverse event". Available: https://agenciabrasil.ebc.com.br/en/saude/noticia/ 2020-11/anvisa-halts-coronavac-studies-after-grave-adverse-event [Accessed 16 Dec 2020]. 